\title{
Assessing Factors Related to Waist Circumference and Obesity: Application of a Latent Variable Model
}

\author{
Sahar Dalvand, ${ }^{1}$ Jalil Koohpayehzadeh, ${ }^{2}$ Masoud Karimlou, ${ }^{1}$ Fereshteh Asgari, ${ }^{2}$ \\ Ali Rafei, ${ }^{2}$ Behjat Seifi, ${ }^{3}$ Seyed Hassan Niksima, ${ }^{4}$ and Enayatollah Bakhshi ${ }^{1}$ \\ ${ }^{1}$ Department of Biostatistics, University of Social Welfare and Rehabilitation Sciences, Tehran 1985713834, Iran \\ ${ }^{2}$ Center for Diseases Control, Ministry of Health and Medical Education, Tehran, Iran \\ ${ }^{3}$ Department of Physiology, School of Medicine, Tehran University of Medical Sciences, Tehran, Iran \\ ${ }^{4}$ Department of Epidemiology and Biostatistics, School of Public Health, Tehran University of Medical Sciences, Tehran, Iran \\ Correspondence should be addressed to Enayatollah Bakhshi; bakhshi@razi.tums.ac.ir
}

Received 26 May 2015; Revised 27 October 2015; Accepted 17 November 2015

Academic Editor: Habibul Ahsan

Copyright (C) 2015 Sahar Dalvand et al. This is an open access article distributed under the Creative Commons Attribution License, which permits unrestricted use, distribution, and reproduction in any medium, provided the original work is properly cited.

\begin{abstract}
Background. Because the use of BMI (Body Mass Index) alone as a measure of adiposity has been criticized, in the present study our aim was to fit a latent variable model to simultaneously examine the factors that affect waist circumference (continuous outcome) and obesity (binary outcome) among Iranian adults. Methods. Data included 18,990 Iranian individuals aged 20-65 years that are derived from the third National Survey of Noncommunicable Diseases Risk Factors in Iran. Using latent variable model, we estimated the relation of two correlated responses (waist circumference and obesity) with independent variables including age, gender, PR (Place of Residence), PA (physical activity), smoking status, SBP (Systolic Blood Pressure), DBP (Diastolic Blood Pressure), CHOL (cholesterol), FBG (Fasting Blood Glucose), diabetes, and FHD (family history of diabetes). Results. All variables were related to both obesity and waist circumference (WC). Older age, female sex, being an urban resident, physical inactivity, nonsmoking, hypertension, hypercholesterolemia, hyperglycemia, diabetes, and having family history of diabetes were significant risk factors that increased WC and obesity. Conclusions. Findings from this study of Iranian adult settings offer more insights into factors associated with high WC and high prevalence of obesity in this population.
\end{abstract}

\section{Introduction}

Obesity has emerged as a public health problem worldwide. Indeed, it is now so common that it is replacing the more traditional public health concerns (i.e., under nutrition and infectious diseases) [1]. The prevalence of obesity has increased in the last century and was dramatically accentuated in recent decades. While Body Mass Index (BMI) has been shown to predict abdominal fat and abdominal subcutaneous fat, waist circumference has been shown to predict visceral fat, thus reinforcing the use of both BMI and waist circumference in clinical practice. An operational definition of obesity, useful in many contexts, is BMI $\geq$ $30.0 \mathrm{~kg} / \mathrm{m}^{2}$, but it should not be used as a conceptual definition. The obesity denotes excess body fat in a large amount, enough to cause a reduction in health or longevity.
This health impairment will not be visible in all cases according to the operational definition used, but the risks caused by obesity impair future health [2]. Measuring waist circumference helps screen for possible health risks that come with overweight and obesity. According to the estimates of the World Health Organization (WHO), overweight and obesity are the fifth risk factor for global deaths, causing approximately 2.8 million deaths per year [3]. Prevalence estimates for overweight and obesity reach 1.4 billion adults over 20 years, obesity alone covering over $10 \%$ of world population [4]. The prevalence of obesity has doubled or even risen threefold in less than two decades [5]. Now, Iran faces growing challenges of aging and noncommunicable diseases. The rising healthcare cost of the estimated number of population with obesity around the world is 1.5 billion in 2012 and it continues to rise [6]. It is estimated that, by 
the year 2015, 2.3 billion people will be overweight and 700 million will be obese [7]. The prevalence of obesity in USA, Canada, Australia, United Kingdom, Iran, and Egypt was 31.8, 24.3, 25.1, 24.9, 21.6, and 34.6, respectively [8]. According to the United States Department of Health and Human Services (HHS) the following individuals are at increased risk for developing chronic diseases: women with a waist circumference of more than 89 centimeters ( 35 inches) and men with a waist circumference of more than 102 centimeters ( 40 inches). However, lower thresholds for waist circumference have been recommended for Asian populations by WHO due to recent research findings. Therefore, those at increased risk for developing chronic disease include Asian women with a waist circumference of more than 79 centimeters ( 31 inches) and Asian men with a waist circumference of more than 89 centimeters (35 inches) [9]. At the same BMI, Asians tend to have a higher percent of body fat and more central adiposity [10]. Department of WHO reported that obesity is increasing in the world [1] and it is also an established health problem in Iran [11]. The top 10 obesity-related diseases include high blood pressure, diabetes, heart disease, high cholesterol levels, cancer, infertility, back pain, skin infections, ulcers, and gallstones [12]. In 2002 about 41,000 new cases of cancer in the United States were estimated to be due to obesity. This means that about 3.2 percent of all new cancers are linked to obesity [13]. In developing countries, increasing overweight and obesity have been reported with greater degree of urbanization [14-17]. Smoking and obesity are leading causes of morbidity and mortality worldwide $[18,19]$. It is widely accepted that hypertension is more common among the obese than among the lean and that a positive relationship exists between the level of blood pressure and the degree of obesity [20]. It is estimated that at least 75 percent of the incidence of hypertension is related directly to obesity [21]. Family history of diabetes has been recognized as an important risk factor of the disease [22]. In 2005 the estimated total numbers of worldwide obese and overweight adults were 396 million and 937 million, respectively. The numbers have differed by race, gender, and geographic location [23]. Apart from medical factors, researchers have focused on nonmedical factors such as sociodemographic and lifestyle factors. Age, sex, physical activity, and socioeconomic state have shown a relation to obesity [24-29]. In the present study our aim was to fit a latent variable model to simultaneously examine the factors that affect WC (continuous outcome) and obesity (binary outcome) among Iranian adults and to provide health professionals with appropriate weightmanagement guidelines for this population.

\section{Materials and Methods}

2.1. Data Source. Data for the present study were derived from the third round of the survey of Noncommunicable Diseases Risk Factors Surveillance in Iran. This populationbased cross-sectional study was conducted by Iran Center for Diseases Control. A cluster sampling design was used to produce representative data for that age range in Iran. The number of clusters in each province was proportional to the size of that province, each cluster comprising 10 men and 10 women. For each province, a total of 50 clusters including 20 participants, two males and two females in each 10 -year age group, were selected using a proportional-to-size systematic sampling scheme. The households addresses were extracted by Iran's Post Company. Eventually, participants were interviewed at their homes after receiving an informed consent by trained healthcare workers. Based on the STEPwise approach of WHO, STEPS is a sequential process, starting with gathering information on key risk factors by the use of questionnaires (Step 1), then moving to simple physical measurements (Step 2), and only then recommending the collection of blood samples for biochemical assessment (Step 3) [30]. Participants were interviewed at their homes by trained healthcare workers from 43 medical schools and a blood sample was taken after receiving a verbal informed consent. After excluding pregnant women, the data analyzed included 18,990 women and men aged $\geq 20$ years.

2.2. Measurements and Variables. Interview phase of the study was performed using a standard questionnaire measuring demographic, behavioral, and physical risk factors proposed by WHO.

2.3. Response Variables. Waist circumference (WC) and obesity were treated as the main response variables of the study.

WC (Continuous Outcome). It is a measure of the distance around the abdomen in centimeter.

Obesity (Binary Outcome). People who are obese have an abnormally high and unhealthy proportion of body fat. To measure obesity, researchers commonly use a formula based on weight and height known as BMI. According to the World Health Organization (WHO), a measurement obtained by dividing a person's weight by the square of the person's height exceeds $30 \mathrm{~kg} / \mathrm{m}^{2}$.

\subsection{Independent Variables}

Age (Year). Information about the respondent's age was based on their self-reported birth year. Adults were stratified into five 10 -year age groups $(20-29,30-39,40-49,50-59$, and $60+$ years).

$P A$. Physical activity is any body movement that works your muscles and requires more energy than resting. PA was a composition measure of different activities as queried in the questionnaire, and participants were stratified into three groups (low/moderate/heavy).

Smoking Status. Smoking status was dichotomized into smokers versus nonsmokers.

Blood Pressure. Normal blood pressure at rest is within the range of 100-140 $\mathrm{mmHg}$ systolic (top reading) and 60$90 \mathrm{mmHg}$ diastolic (bottom reading). High blood pressure is said to be present if it is often at or above $140 / 90 \mathrm{mmHg}$. 
CHOL. Cholesterol, according to sources in the hospital laboratory cut-off point of 200 (cholesterol $\geq 200$ indicates hypercholesterolemia and cholesterol $<200$ is desirable cholesterol), is used.

FBG. Fasting Blood Glucose, as the name suggests, means refraining from eating or drinking any liquids other than water for eight hours. The respondents were categorized into two groups. Adults who had glucose level more than $126 \mathrm{mg} / \mathrm{dL}$ were considered hyperglycemia; others were considered normal FBG.

\subsection{Method}

2.5.1. Overview of Latent Variable Model. According to the method proposed by Teixeira-Pinto and Normand [31] it is assumed that $y_{b}$ and $y_{c}$ are binary and continuous response variable associated with covariates $x_{b}$ and $x_{c}$. The variable $y_{c}$ is assumed to be normally distributed given the covariate $x_{c}$. They developed a multivariate model that takes into account the potential correlation between $y_{b}$ and $y_{c}$. Suppose there is an underlying variable $y_{b i}^{*}$, normally distributed given the covariates $x_{b i}$, that is associated with the binary outcome, $y_{b i}$, in the following way:

$$
y_{b i}= \begin{cases}0, & \text { if } y_{b i}^{*} \leq 0 \\ 1, & \text { if } y_{b i}^{*}>0 .\end{cases}
$$

We can write the regression equation for the binary outcome, $y_{b i}$, as $P\left(y_{b i}=1 \mid x_{b i}, u_{i}\right)=P\left(y_{b i}^{*}>0 \mid x_{b i}, u_{i}\right)=$ $\Phi\left(x_{b i}^{T} \beta_{b}^{*}+u_{i}\right)$, where $\Phi(\cdot)$ represents the cumulative distribution function (cdf) of the standard normal distribution. Probit link function is used for binary response variable. The regression equation for two response variables is written as follows:

$$
\begin{aligned}
\operatorname{probit}\left(P\left(y_{b i}=1 \mid x_{b i}, u_{i}\right)\right) & =X_{b i}^{T} \beta_{b}^{*}+u_{i}, \\
y_{c} \mid x_{c i}, u_{i} & =X_{c i}^{T} \beta_{c}+\sigma_{c} u_{i}+\epsilon_{c i} .
\end{aligned}
$$

That is, $\epsilon_{c i} \sim N(0,1)$ and the latent variable $u_{i} \sim N\left(0, \sigma_{u}^{2}\right)$.

2.6. Statistical Analysis. WC was treated as a continuous outcome variable and obesity as binary outcome variable. The parameters $\beta_{b}^{*}$ in (2) are interpreted as conditional effects on $u_{i}$. For this reason the parameters $\beta_{b}^{*}$ of the latent model cannot be directly compared with the regression parameters of the marginal models. So, estimates for the marginal effects $\widehat{\beta_{b}}$ are obtained using $\beta_{b}=\beta_{b}^{*} / \sqrt{1+\sigma_{u}^{2}}$. For the continuous outcome, $\beta_{c}$ is interpreted as conditional or marginal effects of the covariates. Analyses results were obtained using SAS, version 9.2 .

\section{Results}

Distributions of covariates are shown in Table 1 to make the data presentation complete. Our results showed that the prevalence of obesity was higher among older age groups, females, nonsmokers, and those residing in urban areas. Obesity is frequently observed in people with hyperglycemia, high blood pressure, high cholesterol, and lower PA. About $51.9 \%$ of participants were females and $48.1 \%$ were males. The majority of the sample was between the ages of 30 and 59 years (76.2\%). Urban residents had higher obesity prevalence rates (26.1\%) than rural residents (18.3\%). It was illustrated that nearly $37.7 \%, 23.6 \%$, and $38.7 \%$ of people had low, moderate, and heavy level of PA, respectively. Nearly $7.4 \%$ and $22 \%$ of participants had diabetes and family history of diabetes, respectively. Almost 7\% of people had FBG level more than $126 \mathrm{mg} / \mathrm{dL}$. Nearly $21.5 \%$ of participants had SBP more than $140 \mathrm{mg} / \mathrm{dL}$ and $21.1 \%$ of participants had DBP more than $90 \mathrm{mg} / \mathrm{dL}$. Nearly $37.7 \%$ were hypercholesterolemia and $14.5 \%$ of participants were smokers. Women were more likely to be obese (31.1\%) compared to men (13.6\%).

Results in Table 2 are obtained from fitting latent variable model based on the 18,990 Iranian adults. Among adults, age, being inactive, being an urban resident, being nonsmoker, and being female were directly associated with WC and obesity. Obesity and WC are also directly associated with hyperglycemia, high blood pressure, and high cholesterol. In this sample for continuous outcome (WC), our results show that WC increase to $4.25,6.79,7.51$, and $6.80 \mathrm{~cm}$ for age groups of $30-39,40-49,50-59$, and $60+$ years compared with the age group of $20-29$, respectively. The mean of WC in females is $0.75 \mathrm{~cm}$ more than males and in urban people is $2.94 \mathrm{~cm}$ more than rural people. By using heavy level of PA as the reference group, WC increase to $0.84 \mathrm{~cm}$ for low level of PA. Using smokers as the reference group, the mean of WC increases to $3.10 \mathrm{~cm}$ for nonsmokers. The mean of WC increases to 2.16 and $2.82 \mathrm{~cm}$ among people with high level of SBP and DBP, respectively. In adults with high level of $\mathrm{CHOL}$, the mean of WC increases to $3.66 \mathrm{~cm}$ compared with normal group. Among adults with hyperglycemia, the mean of WC increases to $2 \mathrm{~cm}$ compared to others. The mean of WC for adults with diabetes and FHD increase to 3.11 and $1.97 \mathrm{~cm}$, respectively.

Our results in Table 2 also show that, for binary outcome (obesity), adults aged 30-39, 40-49, 50-59, and 60+ years increase the standard normal coefficient of obesity by 0.62 , $0.66,0.63$, and 0.58 , respectively, compared with age group of 20-29. Female sex increases the standard normal coefficient of obesity by 0.47 . Our results show that residency in an urban area increases the standard normal coefficient of obesity by 0.41 . Having a low level of PA increases the standard normal coefficient of obesity by 0.52 compared with heavy level. Being nonsmoker increases the standard normal coefficient of obesity by 0.61 . Adults with high level of SBP, DBP, CHOL, FBG, and FHD increase the standard normal coefficient of obesity by $0.12,0.27,0.28,0.09$, and 0.19 , respectively.

\section{Discussion}

In this national survey, we assessed associations between varieties of medical and nonmedical factors with WC and obesity in 18990 adults (aged $\geq 20$ years) in Iran by using latent variable model. In our study, positive association was found between increased obesity and older age. Furthermore, the mean of WC increased with increasing age but the standard 
TABLE 1: Descriptive characteristics of waist circumference and obesity across study variable levels.

\begin{tabular}{|c|c|c|c|c|c|c|}
\hline \multirow{2}{*}{ Variables } & \multicolumn{2}{|c|}{ Waist circumference } & \multicolumn{3}{|c|}{ Obesity } & \multirow{2}{*}{$P$ value } \\
\hline & Mean & SD & No & Percent & Total & \\
\hline \multicolumn{7}{|l|}{ Age } \\
\hline $20-29$ & 82.86 & 12.36 & 254 & 11.5 & 2206 & \multirow{5}{*}{$<0.001$} \\
\hline $30-39$ & 87.56 & 12.66 & 926 & 20.2 & 4584 & \\
\hline $40-49$ & 91.22 & 13.26 & 1284 & 26.3 & 4888 & \\
\hline $50-59$ & 93.04 & 13.43 & 1312 & 26.2 & 5006 & \\
\hline $60+$ & 92.85 & 13.63 & 532 & 23.1 & 2306 & \\
\hline \multicolumn{7}{|l|}{ Gender } \\
\hline Male & 89.52 & 12.90 & 1245 & 13.6 & 9130 & \multirow[t]{2}{*}{$<0.001$} \\
\hline Female & 90.53 & 14.06 & 3063 & 31.1 & 9860 & \\
\hline \multicolumn{7}{|l|}{ PR } \\
\hline Urban & 91.66 & 13.39 & 2792 & 26.1 & 10706 & \multirow[t]{2}{*}{$<0.001$} \\
\hline Rural & 87.96 & 13.41 & 1516 & 18.3 & 8284 & \\
\hline \multicolumn{7}{|l|}{ Physical activity } \\
\hline Low & 91.02 & 14.03 & 1919 & 26.8 & 7159 & $<0.001$ \\
\hline Moderate & 90.41 & 13.15 & 1028 & 23.0 & 4475 & 0.061 \\
\hline Heavy & 88.87 & 13.15 & 1361 & 18.5 & 7356 & $<0.001$ \\
\hline \multicolumn{7}{|l|}{ Smoking } \\
\hline Nonsmoker & 87.27 & 13.03 & 297 & 10.8 & 2760 & \multirow[t]{2}{*}{$<0.001$} \\
\hline Smoker & 90.52 & 13.55 & 4011 & 24.7 & 16230 & \\
\hline \multicolumn{7}{|l|}{ SBP } \\
\hline Normal & 88.66 & 13.24 & 3031 & 20.3 & 14906 & \multirow[t]{2}{*}{$<0.001$} \\
\hline High & 95.11 & 13.33 & 1277 & 31.3 & 4084 & \\
\hline \multicolumn{7}{|l|}{ DBP } \\
\hline Normal & 88.71 & 13.26 & 2951 & 19.7 & 14975 & \multirow[t]{2}{*}{$<0.001$} \\
\hline High & 95.03 & 13.33 & 1357 & 33.8 & 4015 & \\
\hline \multicolumn{7}{|l|}{ CHOL } \\
\hline Normal & 87.94 & 13.31 & 2143 & 18.1 & 11825 & \multirow[t]{2}{*}{$<0.001$} \\
\hline High & 93.52 & 13.16 & 2165 & 30.2 & 7165 & \\
\hline \multicolumn{7}{|l|}{ FBG } \\
\hline Normal & 89.54 & 13.42 & 3850 & 21.8 & 17672 & \multirow[t]{2}{*}{$<0.001$} \\
\hline High & 96.79 & 13.03 & 458 & 34.7 & 1318 & \\
\hline \multicolumn{7}{|l|}{ Diabetes } \\
\hline Yes & 97.23 & 12.02 & 499 & 35.4 & 1409 & \multirow[t]{2}{*}{$<0.001$} \\
\hline No & 89.47 & 13.47 & 3809 & 21.7 & 1758 & \\
\hline \multicolumn{7}{|l|}{ FHD } \\
\hline Yes & 92.68 & 13.24 & 1207 & 29.6 & 4076 & \multirow[t]{2}{*}{$<0.001$} \\
\hline No & 89.32 & 13.51 & 3101 & 20.8 & 14914 & \\
\hline
\end{tabular}

normal coefficient of obesity went up among adults aged 20-49 years and then it decreased for ages above 50 years. Changes in food intake, energy expenditure, appetite, and body composition that occurs with ageing could be related to the effect of age on obesity [32]. Different studies showed that overweight and obesity were associated with increased age in which there are hormonal changes and a common decrease in physical activity [33-35]. Although obesity prevalence increased in the world, there were differences between men and women in some regions and countries. Almost in all studies in Iran the joint frequency of obesity in women was more than men in all ages [36]. Generally, $13.6 \%$ of men in this study were obese, a statistic similar to reports from another study of Iran [37]. Gender differences were also present in this analysis for the adult Iranian population. Women were more likely to be obese than men. Statistically significant differences were found between adult men and women. Similar findings have been reported by others [36, 
TABLE 2: Estimates, standard errors, and $P$ values of the association between factors and waist circumference and obesity obtained from latent variable model for Iranian adults.

\begin{tabular}{|c|c|c|c|c|c|c|c|}
\hline \multirow{2}{*}{ Variables } & \multicolumn{2}{|c|}{ Waist circumference } & \multirow{2}{*}{$P$ value } & \multicolumn{3}{|c|}{ Obesity } & \multirow{2}{*}{$P$ value } \\
\hline & Estimate & SE & & Estimate & SE & $\mathrm{SN}^{* *}$ & \\
\hline \multicolumn{8}{|l|}{ Age } \\
\hline $20-29$ & $* * *$ & & & $* * *$ & & & \\
\hline $30-39$ & 4.25 & 0.32 & & 0.31 & 0.04 & 0.62 & \\
\hline $40-49$ & 6.79 & 0.33 & $<0.001$ & 0.42 & 0.04 & 0.66 & $<0.001$ \\
\hline $50-59$ & 7.51 & 0.33 & & 0.32 & 0.04 & 0.63 & \\
\hline $60+$ & 6.80 & 0.39 & & 0.19 & 0.05 & 0.58 & \\
\hline \multicolumn{8}{|l|}{ Gender } \\
\hline Female & 0.75 & 0.21 & $<0.001$ & 0.47 & 0.02 & 0.68 & \\
\hline Male & $* * *$ & & & $* * *$ & & & $<0.001$ \\
\hline \multicolumn{8}{|l|}{ PR } \\
\hline Urban & 2.94 & 0.19 & $<0.001$ & 0.25 & 0.02 & 0.41 & $<0.001$ \\
\hline Rural & $* * *$ & & & $* * *$ & & & \\
\hline \multicolumn{8}{|l|}{$\mathrm{PA}$} \\
\hline Low & 0.84 & 0.22 & $<0.001$ & 0.060 & 0.02 & 0.52 & 0.02 \\
\hline Moderate & 0.24 & 0.70 & 0.07 & 0.007 & 0.03 & 0.50 & 0.79 \\
\hline Heavy & $* * *$ & & & $* * *$ & & & \\
\hline \multicolumn{8}{|l|}{ Smoking } \\
\hline Smoker & $* * *$ & & & $* * *$ & & & \\
\hline Nonsmoker & 3.10 & 0.28 & $<0.001$ & 0.27 & 0.04 & 0.61 & $<0.001$ \\
\hline \multicolumn{8}{|l|}{ SBP } \\
\hline Normal & $* * *$ & & & $* * *$ & & & \\
\hline High & 2.16 & 0.29 & $<0.001$ & 0.12 & 0.03 & 0.55 & $<0.001$ \\
\hline \multicolumn{8}{|l|}{ DBP } \\
\hline Normal & $* * *$ & & & $* * *$ & & & \\
\hline High & 2.82 & 0.28 & $<0.001$ & 0.27 & 0.03 & 0.61 & $<0.001$ \\
\hline \multicolumn{8}{|l|}{$\mathrm{CHOL}$} \\
\hline Normal & $* * *$ & & & $* * *$ & & & \\
\hline High & 3.66 & 0.19 & $<0.001$ & 0.28 & 0.02 & 0.61 & $<0.001$ \\
\hline \multicolumn{8}{|l|}{ FBG } \\
\hline Normal & $* * *$ & & & $* * *$ & & & \\
\hline High & 2.00 & 0.41 & $<0.001$ & 0.09 & 0.04 & 0.54 & 0.03 \\
\hline \multicolumn{8}{|l|}{ Diabetes } \\
\hline Yes & 3.11 & 0.41 & $<0.001$ & 0.16 & 0.04 & 0.44 & $<0.001$ \\
\hline No & $* * *$ & & & $* * *$ & & & \\
\hline \multicolumn{8}{|l|}{ FHD } \\
\hline Yes & 1.97 & 0.23 & $<0.001$ & 0.19 & 0.03 & 0.43 & $<0.001$ \\
\hline No & $* * *$ & & & $* * *$ & & & \\
\hline
\end{tabular}

${ }^{* *}$ Standard normal coefficient.

${ }^{* * *}$ Comparator group.

38-42]. Factors related to lifestyle may therefore be the reason for the high prevalence of obesity in women [40, 43]. Our results showed the differences between obesity and WC in urban and rural people. This could be a marker of bigger differences in urban/rural lifestyles in Iranian population, due to the recent acceleration of urbanization in Iran. Our findings did not agree with a study of ten European countries, in which no significant differences between urban and rural areas regarding obesity were detected in 9 of the 10 countries examined [15]. This etiology is multifactorial with genetic influences and environmental, socioeconomic, and behavioral and/or psychological causes playing a significant 
role and a relative increase in both WC and obesity. In line with some study, our results showed an inverse relationship between physical activity and obesity. Lack of PA and a hyper caloric nutrition are the main reason for obesity. PA is useful to burn calories and keep the muscular mass and increase the PA again [44]. So, most public health interventions attempt to create a negative energy balance by increasing PA. Rural residence in developing countries may be associated with more physical labor than urban settings and possibly obesity has lower prevalence in rural areas $[14,16,45]$. The relation between smoking and obesity is incompletely understood. Although most studies have indicated that smokers on average have lower body weights $[46,47]$, a few have reported that smoking and body weight are positively correlated [48]. Nicotine acutely increases energy expenditure and could reduce appetite, which likely explains why smokers tend to have lower body weight than nonsmokers and why smoking cessation is frequently followed by weight gain. Waist circumference (WC) is an indicator of the amount of visceral adipose tissue (VAT). A greater amount of VAT is related to the metabolic syndrome, diabetes, and cardiovascular diseases [49]. Cross-sectional studies indicate that WC is higher in smokers compared with nonsmokers [50-54]. Our results on the association between smoking and obesity are basically in agreement with those of other studies [24, 55]. Data from the Honolulu Heart Program [56] and the Japanese Data Bank Survey [57] indicate that obesity and high blood pressure continue to be correlated, even in old age. Obesity is associated with an increased risk of cardiovascular disease, but this requires that obesity is combined with hypertension. In obese subjects, the cardiovascular risk is not significantly increased unless hypertension is present [58]. The current study showed that individuals with the highest waist circumference quartile had 2-fold increased risk for hypertension compared with individuals with the lowest quartile [59]. We found a positive relationship between WC and obesity with hypertension. Both Framingham and Tecumseh studies have shown that future weight gain is significantly greater in hypertensive patients than in normotensive subjects [60,61]. Many studies have shown that weight loss is effective in lowering the blood pressure [62-64]. Some studies showed that individuals with higher BMI have $14 \%$ chance of hypercholesterolemia [65]. Hypercholesterolemia is frequently found in patients with obesity, so that the average serum cholesterol level is significantly higher in overweight subjects than in lean ones, and usually a significant correlation exists between total cholesterol and obesity. The WC and possibly other body size measurements were independently related to the risk for high cholesterol, even among nonobese subjects [66]. Gostynski et al. [67] reported a strong positive association between hypercholesterolaemia and BMI. This finding corresponds well with the observations made in other cross-sectional studies, for example, the LRC Program Prevalence Study [68]. Our results are consistent with the hypothesis that with increase in obesity/WC the risk of hypercholesterolemia acutely increases. The present analysis had also revealed a positive association between WC and obesity with FHD and FBG. Okosun et al. [69] assessed the association of WC and risk of hypertension and type 2 diabetes in populations from several different African origins. They found that the higher categories of waist circumference were associated with larger excess in the prevalence of hyperglycemia in the presence of a family history of diabetes. If the association between obesity and hyperglycemia is different in individuals with a parental history of diabetes, this may affect decisions about weight reduction and screening for diabetes [70]. Although the reason for this difference is unclear, differences in other lifestyles or race might be important factors. These findings were in an agreement with some study [71].

4.1. Strengths and Limitations. A major strength of this study is that it included data from the Iranian population and the findings are applicable to populations in Asian countries. Despite this, because the use of BMI (Body Mass Index) alone as a measure of adiposity has been criticized, we used a latent variable model to simultaneously examine the factors that affect WC and obesity. We adjusted our analyses for a number of putative confounders including medical and nonmedical factors.

Consideration must be given to the potential limitations of this study, including its cross-sectional approach. We cannot establish a causal association between factors and obesity and WC or the direction of association. Although we adjusted our analyses for confounders, we have not included in our model other factors associated with obesity, such as marital status, dietary consumption, family income, and genotype because of the lack of information on these variables in this study.

\section{Conclusion}

In recent decades, risk factors for preventing obesity have been found. Obesity is now growing at an alarming rate reaching epidemic proportions worldwide thus increasing morbidity and mortality rates for chronic disease. Based on our findings, the lower prevalence of obesity among physically active Iranians was expected. As demonstrated, in adults obesity is real and we believe that this is belated time to create a healthy lifestyle. Unhealthy diet, physical inactivity, excess weight, and diabetes are taken into account as major causes of obesity. Findings from this study of Iranian adult settings offer more insights into factors associated with high $\mathrm{WC}$ and high prevalence of obesity in this population.

\section{Abbreviations}

WC: Waist circumference

PR: $\quad$ Place of Residence

PA: Physical activity

SBP: Systolic Blood Pressure

DBP: Diastolic Blood Pressure

CHOL: Cholesterol

FBG: Fasting Blood Glucose

FHD: Family history of diabetes

NCD: Noncommunicable disease

WHO: World Health Organization. 


\section{Disclaimer}

The views and opinions expressed in this paper are those of the authors and not necessarily those of the Center for Diseases Control.

\section{Conflict of Interests}

None of the authors had any conflict of interests.

\section{Acknowledgments}

The STEPS Survey in Iran is a WHO collaborative study. The authors acknowledge the Center for Diseases Control for their data, coordinated at the Iranian Ministry of Health and Medical Education. They are grateful to all the participants of this study. This study was approved by the Ethic Committee of the University of Social Welfare and Rehabilitation Sciences.

\section{References}

[1] World Health Organization, "Obesity: preventing and managing the global epidemic," Report of a WHO Consultation (WHO Technical Report Series 894), World Health Organization, 2000.

[2] V. Silva and A. J. Grande, "Weight loss management through exercise based on guideline recommendation: a case series from SRF-YMCA study," Obesity and Weight Loss Therapy, vol. 3, no. 5, article 4, 2013.

[3] World Health Organization, "Obesity and overweight," Fact Sheet 311, World Health Organization, 2014, http://www.who.int/ mediacentre/factsheets/fs311/en/.

[4] European Association for the Study of Obesity, "Obesity Facts \& Figures," January 2015, http://easo.org/obesity-facts-figures.

[5] P. T. James, N. Rigby, and R. Leach, "The obesity epidemic, metabolic syndrome and future prevention strategies," European Journal of Cardiovascular Prevention and Rehabilitation, vol. 11, no. 1, pp. 3-8, 2004.

[6] W. Aekplakorn, R. Inthawong, P. Kessomboon et al., "Prevalence and trends of obesity and association with socioeconomic status in Thai adults: national health examination surveys, 19912009," Journal of Obesity, vol. 2014, Article ID 410259, 8 pages, 2014.

[7] Wikipedia, "Obesity in the Middle East and North Africa," 2014, https://en.wikipedia.org/wiki/Obesity_in_the_Middle_East_ and_North_Africa.

[8] World Health Organization, Overweight, World Health Organization, 2015, http://www.who.int/gho/ncd/risk_factors/overweight_text/en/.

[9] NHLBI Obesity Education Initiative Expert Panel on the Identification-Evaluation and Treatment of Obesity in Adults (US), Clinical Guidelines on the Identification, Evaluation, and Treatment of Overweight and Obesity in Adults: The Evidence Report, National Heart, Lung, and Blood Institute, Bethesda, Md, USA, 1998, http:/www.ncbi.nlm.nih.gov/books/NBK2003/.

[10] P. Deurenberg, M. Deurenberg-Yap, and S. Guricci, "Asians are different from Caucasians and from each other in their body mass index/body fat per cent relationship," Obesity Reviews, vol. 3, no. 3, pp. 141-146, 2002.
[11] A. Rashidi, B. Mohammadpour-Ahranjani, M. R. Vafa, and M. Karandish, "National prevalence of obesity: prevalence of obesity in Iran," Obesity Reviews, vol. 6, no. 3, pp. 191-192, 2005.

[12] Top 10 Obesity-Related Diseases-The Truth About Being Obese, Medical Weight Loss Resources, Winter Park, Fla, USA, 2014, http://www.mediweightlossclinics.com/patients/ resources/articles/obesity-facts/.

[13] A. P. Polednak, "Trends in incidence rates for obesity-associated cancers in the US," Cancer Detection and Prevention, vol. 27, no. 6, pp. 415-421, 2003.

[14] United States Cardiovascular and Cardiopulmonary Epidemiology Research Group, "An epidemiological study of cardiovascular and cardiopulmonary disease risk factors in four populations in the People's Republic of China: baseline report from the P.R.C.-U.S.A. collaborative study," Circulation, vol. 85, no. 3, pp. 1083-1096, 1992.

[15] I. Peytremann-Bridevaux, D. Faeh, and B. Santos-Eggimann, "Prevalence of overweight and obesity in rural and urban settings of 10 European countries," Preventive Medicine, vol. 44, no. 5, pp. 442-446, 2007.

[16] H. Campos, L. Mata, X. Siles, M. Vives, J. M. Ordovas, and E. J. Schaefer, "Prevalence of cardiovascular risk factors in rural and urban Costa Rica," Circulation, vol. 85, no. 2, pp. 648-658, 1992.

[17] C. A. Monteiro, L. Mondini, A. L. Medeiros de Souza, and B. M. Popkin, "The nutrition transition in Brazil," European Journal of Clinical Nutrition, vol. 49, no. 2, pp. 105-113, 1995.

[18] A. H. Mokdad, J. S. Marks, D. F. Stroup, and J. L. Gerberding, "Actual causes of death in the United States, 2000," The Journal of the American Medical Association, vol. 291, no. 10, pp. 1238$1245,2004$.

[19] D. W. Haslam and W. P. T. James, “Obesity," The Lancet, vol. 366, no. 9492, pp. 1197-1209, 2005.

[20] H. M. Whyte, "Blood pressure and obesity," Circulation, vol. 19, no. 4, pp. 511-516, 1959.

[21] American Heart Association, Overweight and Obesity Statistics-2009 Update, American Heart Association, Dallas, Tex, USA, 2009.

[22] A. M. Annis, M. S. Caulder, M. L. Cook, and D. Duquette, "Family history, diabetes, and other demographic and risk factors among participants of the National Health and Nutrition Examination Survey 1999-2002," Preventing Chronic Disease, vol. 2, no. 2, p. 12, 2005.

[23] C. L. Ogden, K. M. Flegal, M. D. Carroll, and C. L. Johnson, "Prevalence and trends in overweight among US children and adolescents, 1999-2000," The Journal of the American Medical Association, vol. 288, no. 14, pp. 1728-1732, 2002.

[24] F. Asgari, A. Biglarian, B. Seifi, A. Bakhshi, H. H. Miri, and E. Bakhshi, "Using quadratic inference functions to determine the factors associated withobesity: findings from the STEPS Survey in Iran," Annals of Epidemiology, vol. 23, no. 9, pp. 534-538, 2013.

[25] J. A. Greenberg, "Obesity and early mortality in the United States," Obesity, vol. 21, no. 2, pp. 405-412, 2013.

[26] J. A. Steeves, D. R. Bassett Jr., D. L. Thompson, and E. C. Fitzhugh, "Relationships of occupational and non-occupational physical activity to abdominal obesity," International Journal of Obesity, vol. 36, no. 1, pp. 100-106, 2012.

[27] R. A. Mekary, D. Feskanich, S. Malspeis, F. B. Hu, W. C. Willett, and A. E. Field, "Physical activity patterns and prevention of weight gain in premenopausal women," International Journal of Obesity, vol. 33, no. 9, pp. 1039-1047, 2009. 
[28] E. Bakhshi, B. Seifi, A. Biglarian, and K. Mohammad, "Changes in body mass index across age groups in iranian women: results from the national health survey," Journal of Nutrition and Metabolism, vol. 2012, Article ID 848403, 9 pages, 2012.

[29] E. Bakhshi, M. R. Eshraghian, K. Mohammad, and B. Seifi, "A comparison of two methods for estimating odds ratios: results from the National Health Survey," BMC Medical Research Methodology, vol. 8, article 78, 2008.

[30] A. Esteghamati, A. Meysamie, O. Khalilzadeh et al., "Third national surveillance of risk factors of non-communicable diseases (SuRFNCD-2007) in Iran: methods and results on prevalence of diabetes, hypertension, obesity, central obesity, and dyslipidemia," BMC Public Health, vol. 9, article 167, 2009.

[31] A. Teixeira-Pinto and S.-L. T. Normand, "Correlated bivariate continuous and binary outcomes: issues and applications," Statistics in Medicine, vol. 28, no. 13, pp. 1753-1773, 2009.

[32] E. Bakhshi, B. Seifi, A. Biglarian, and K. Mohammad, "Factors associated with obesity in Iranian elderly people: results from the national health survey," BMC Research Notes, vol. 4, article 538, 2011.

[33] V. H. H. Goh, T. Y. Y. Tong, H. P. P. Mok, and B. Said, "Differential impact of aging and gender on lipid and lipoprotein profiles in a cohort of healthy Chinese Singaporeans," Asian Journal of Andrology, vol. 9, no. 6, pp. 787-794, 2007.

[34] A. Ghadiri-Anari, M. Jafarizadah, A. Zare, H. MozaffariKhosravi, M. Afkhami-Ardekani, and A. ShojaoddinyArdekani, "Prevalence of obesity and overweight among adults in Iranian population (Yazd Province)," Iranian Journal of Diabetes and Obesity, vol. 5, no. 2, pp. 67-70, 2013.

[35] H. M. Seagle, H. Wyatt, and J. O. Hill, "Obesity: overview of treatments and interventions," in Nutrition in the Prevention and Treatment of Disease, A. M. Coulston, C. Rock, and E. R. Monsen, Eds., pp. 465-681, Academic Press, San Diego, Calif, USA, 1st edition, 2001.

[36] M. Maddah, "The factors associated with adult obesity in Iran: a review," Iranian Journal of Nutrition Sciences \& Food Technology, vol. 7, no. 1, p. 9, 2012 (Persian).

[37] P. Mirmiran and F. Azizi, "Obesity," in Epidemiology and Control of Common Disease in Iran, H. Hatami, M. Janghorbani, and F. Azizi, Eds., pp. 56-59, Eshtiagh, Tehran, Iran, 2nd edition, 1999 (Persian).

[38] S. Dasgupta and S. C. Hazra, "The utility of waist circumference in assessment of obesity," Indian Journal of Public Health, vol. 43, no. 4, pp. 132-135, 1999.

[39] E. Bakhshi, K. Mohammad, M. R. Eshraghian, and B. Seifi, "Factors related to obesity among Iranian men: results from the National Health Survey," Public Health Nutrition, vol. 13, no. 9, pp. 1389-1394, 2010.

[40] L. Azadbakht, P. Mirmiran, N. Shiva, and F. Azizi, "General obesity and central adiposity in a representative sample of Tehranian adults: prevalence and determinants," International Journal for Vitamin and Nutrition Research, vol. 75, no. 4, pp. 297-304, 2005.

[41] K. O. Hajian-Tilaki and B. Heidari, "Prevalence of obesity, central obesity and the associated factors in urban population aged 20-70 years, in the north of Iran: a population-based study and regression approach," Obesity Reviews, vol. 8, no. 1, pp. 3-10, 2007.

[42] A. Akhavan Tabib, R. Kelishadie, G. H. Sadri, B. Sabet, H. R. Toluei, and A. Baghaei, "Healthy heart program: obesity in center of Iran," The Journal of Qazvin University of Medical Sciences, vol. 7, no. 2, pp. 27-35, 2003 (Persian).
[43] F. Pérez-Bravo, E. Carrasco, J. L. Santos, M. Calvillán, G. Larenas, and C. Albala, "Prevalence of type 2 diabetes and obesity in rural Mapuche population from Chile," Nutrition, vol. 17, no. 3, pp. 236-238, 2001.

[44] T. Kortmann and G. Schumacher, "Physical activity in obesity and overweight," Therapeutische Umschau. Revue Thérapeutique, vol. 70, no. 2, pp. 113-117, 2013.

[45] M. Neovius and F. Rasmussen, "Place of residence and obesity in 1,578,694 young swedish men between 1969 and 2005," Obesity, vol. 16, no. 3, pp. 671-676, 2008.

[46] E. Bakhshi, J. Koohpayehzadeh, B. Seifi et al., "Obesity and related factors in Iran: the STEPS Survey, 2011," Iranian Red Crescent Medical Journal, vol. 17, no. 6, Article ID e22479, 2015.

[47] K. Patel, M. K. Hargreaves, J. Liu et al., "Relationship between smoking and obesity among women," American Journal of Health Behavior, vol. 35, no. 5, pp. 627-636, 2011.

[48] C. G. Healton, D. Vallone, K. L. McCausland, H. Xiao, and M. P. Green, "Smoking, obesity, and their co-occurrence in the United States: cross sectional analysis," British Medical Journal, vol. 333, no. 7557, pp. 25-26, 2006.

[49] T. S. Han, N. Sattar, and M. Lean, "ABC of obesity: assessment of obesity and its clinical implications," British Medical Journal, vol. 333, no. 7570, pp. 695-698, 2006.

[50] C. Bamia, A. Trichopoulou, D. Lenas, and D. Trichopoulos, "Tobacco smoking in relation to body fat mass and distribution in a general population sample," International Journal of Obesity, vol. 28, no. 8, pp. 1091-1096, 2004.

[51] H. Shimokata, D. C. Muller, and R. Andres, "Studies in the distribution of body fat. III. Effects of cigarette smoking," Journal of the American Medical Association, vol. 261, no. 8, pp. 1169-1173, 1989.

[52] E. Barrett-Connor and K.-T. Khaw, "Cigarette smoking and increased central adiposity," Annals of Internal Medicine, vol. 111, no. 10, pp. 783-787, 1989.

[53] R. Rosmond and P. Björntorp, "Psychosocial and socioeconomic factors in women and their relationship to obesity and regional body fat distribution," International Journal of Obesity, vol. 23, no. 2, pp. 138-145, 1999.

[54] D. Canoy, N. Wareham, R. Luben et al., "Cigarette smoking and fat distribution in 21,828 british men and women: a PopulationBased Study," Obesity Research, vol. 13, no. 8, pp. 1466-1475, 2005.

[55] Y. S. Mineur, A. Abizaid, Y. Rao et al., "Nicotine decreases food intake through activation of POMC neurons," Science, vol. 332, no. 6035, pp. 1330-1332, 2011.

[56] K. H. Masaki, J. D. Curb, D. Chiu, H. Petrovitch, and B. L. Rodriguez, "Association of body mass index with blood pressure in elderly Japanese American men. The Honolulu Heart Program," Hypertension, vol. 29, no. 2, pp. 673-677, 1997.

[57] K. Matsumura, T. Ansai, S. Awano et al., "Association of body mass index with blood pressure in 80 -year-old subjects," Journal of Hypertension, vol. 19, no. 12, pp. 2165-2169, 2001.

[58] F. Thomas, K. Bean, B. Pannier, J.-M. Oppert, L. Guize, and A. Benetos, "Cardiovascular mortality in overweight subjects: the key role of associated risk factors," Hypertension, vol. 46, no. 4, pp. 654-659, 2005.

[59] T. Y. Warren, S. Wilcox, M. Dowda, and M. Baruth, "Independent association of waist circumference with hypertension and diabetes in African American women, South Carolina, 20072009," Preventing Chronic Disease, vol. 9, no. 5, Article ID 110170, 9 pages, 2012. 
[60] S. Julius, M. Valentini, and P. Palatini, "Overweight and hypertension: a 2-way street?” Hypertension, vol. 35, no. 3, pp. 807$813,2000$.

[61] K. Narkiewicz, "Obesity and hypertension-the issue is more complex than we thought," Nephrology Dialysis Transplantation, vol. 21, no. 2, pp. 264-267, 2006.

[62] S. Wassertheil-Smoller, M. D. Blaufox, A. S. Oberman, H. G. Langford, B. R. Davis, and J. Wylie-Rosett, "The Trial of Antihypertensive Interventions and Management (TAIM) study: adequate weight loss, alone and combined with drug therapy in the treatment of mild hypertension," Archives of Internal Medicine, vol. 152, no. 1, pp. 131-136, 1992.

[63] V. I. Lasser, J. M. Raczynski, V. J. Stevens et al., "Trials of Hypertension Prevention, phase II. Structure and content of the weight loss and dietary sodium reduction interventions. Trials of Hypertension Prevention (TOHP) Collaborative Research Group," Annals of Epidemiology, vol. 5, no. 2, pp. 156-164, 1995.

[64] P. J. Elmer, R. Grimm Jr., B. Laing et al., "Lifestyle intervention: results of the Treatment of Mild Hypertension Study (TOMHS)," Preventive Medicine, vol. 24, no. 4, pp. 378-388, 1995.

[65] S. Tyrovolas, C. Lionis, A. Zeimbekis et al., "Increased body mass and depressive symptomatology are associated with hypercholesterolemia, among elderly individuals; results from the MEDIS study," Lipids in Health and Disease, vol. 8, article 10, 2009.

[66] P. T. Williams, "Changes in body weight and waist circumference affect incident hypercholesterolemia during 7 years of follow-up," Obesity, vol. 16, no. 9, pp. 2163-2168, 2008.

[67] M. Gostynski, F. Gutzwiller, K. Kuulasmaa et al., "Analysis of the relationship between total cholesterol, age, body mass index among males and females in the WHO MONICA Project," International Journal of Obesity, vol. 28, no. 8, pp. 1082-1090, 2004.

[68] The Lipid Reaserch Clinics Program Epidemiology Committee, "Plasma lipid distributions in selected North American populations: the Lipid Research Clinics Program Prevalence Study," Circulation, vol. 60, no. 2, pp. 427-439, 1979.

[69] I. S. Okosun, R. S. Cooper, C. N. Rotimi, B. Osotimehin, and T. Forrester, "Association of waist circumference with risk of hypertension and type 2 diabetes in Nigerians, Jamaicans, and African-Americans," Diabetes Care, vol. 21, no. 11, pp. 1836-1842, 1998.

[70] E. van 'T Riet, J. M. Dekker, Q. Sun, G. Nijpels, F. B. Hu, and R. M. van Dam, "Role of adiposity and lifestyle in the relationship between family history of diabetes and 20-year incidence of type 2 diabetes in U.S. women," Diabetes Care, vol. 33, no. 4, pp. 763767, 2010.

[71] K. Ishikawa-Takata, T. Ohta, K. Moritaki, T. Gotou, and S. Inoue, "Obesity, weight change and risks for hypertension, diabetes and hypercholesterolemia in Japanese men," European Journal of Clinical Nutrition, vol. 56, no. 7, pp. 601-607, 2002. 


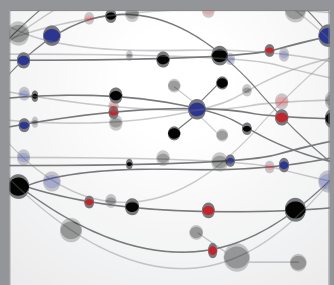

The Scientific World Journal
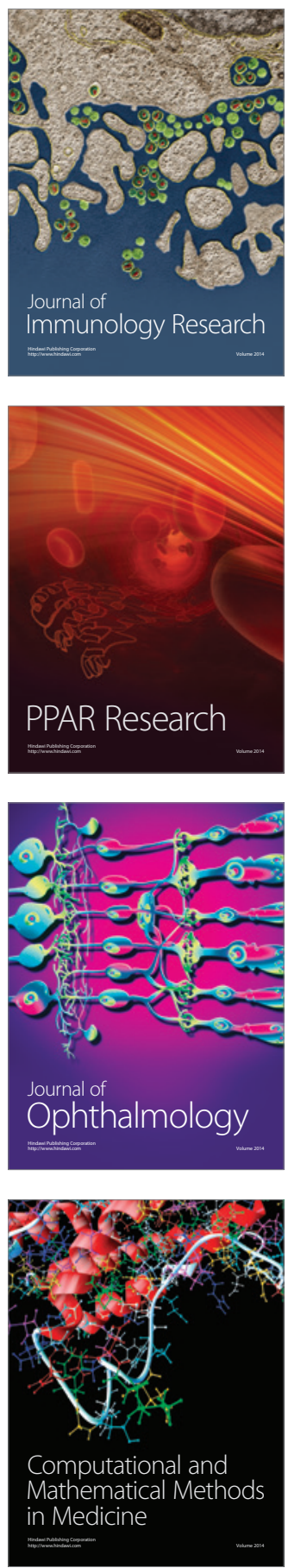

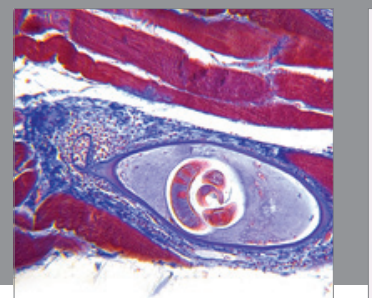

Gastroenterology

Research and Practice
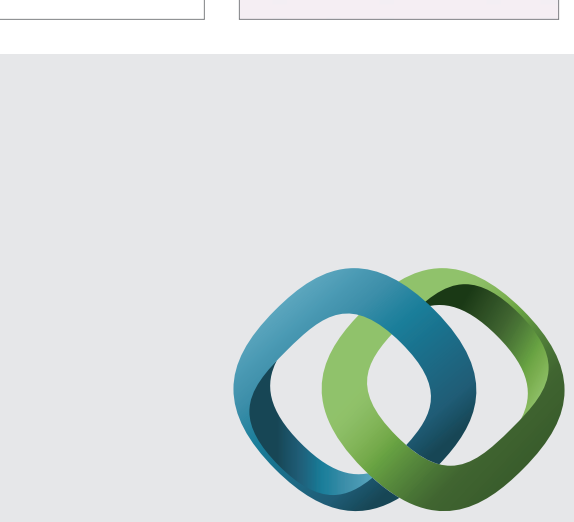

\section{Hindawi}

Submit your manuscripts at

http://www.hindawi.com
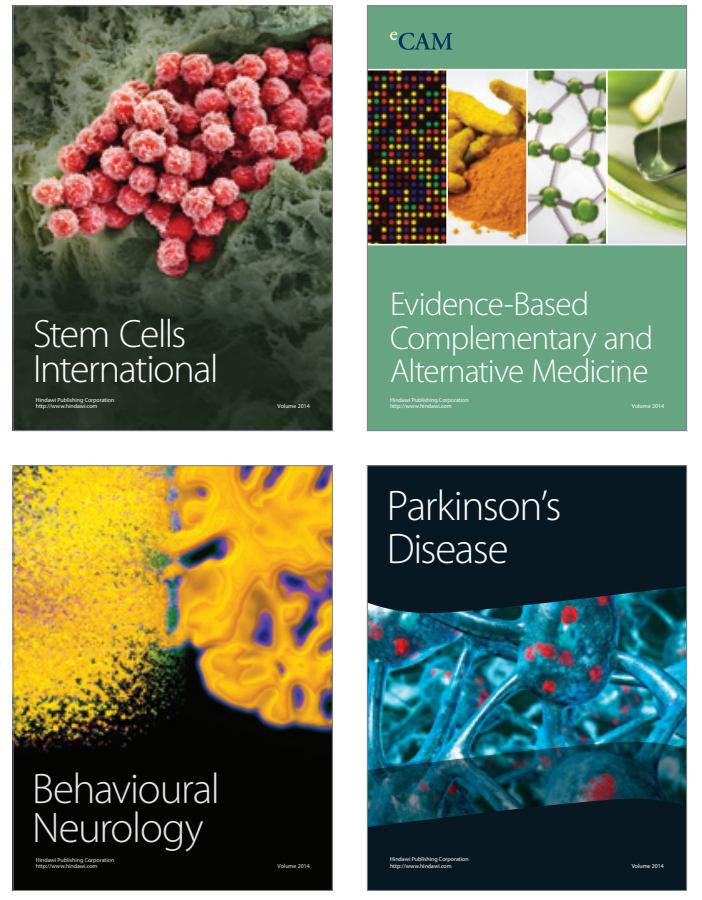
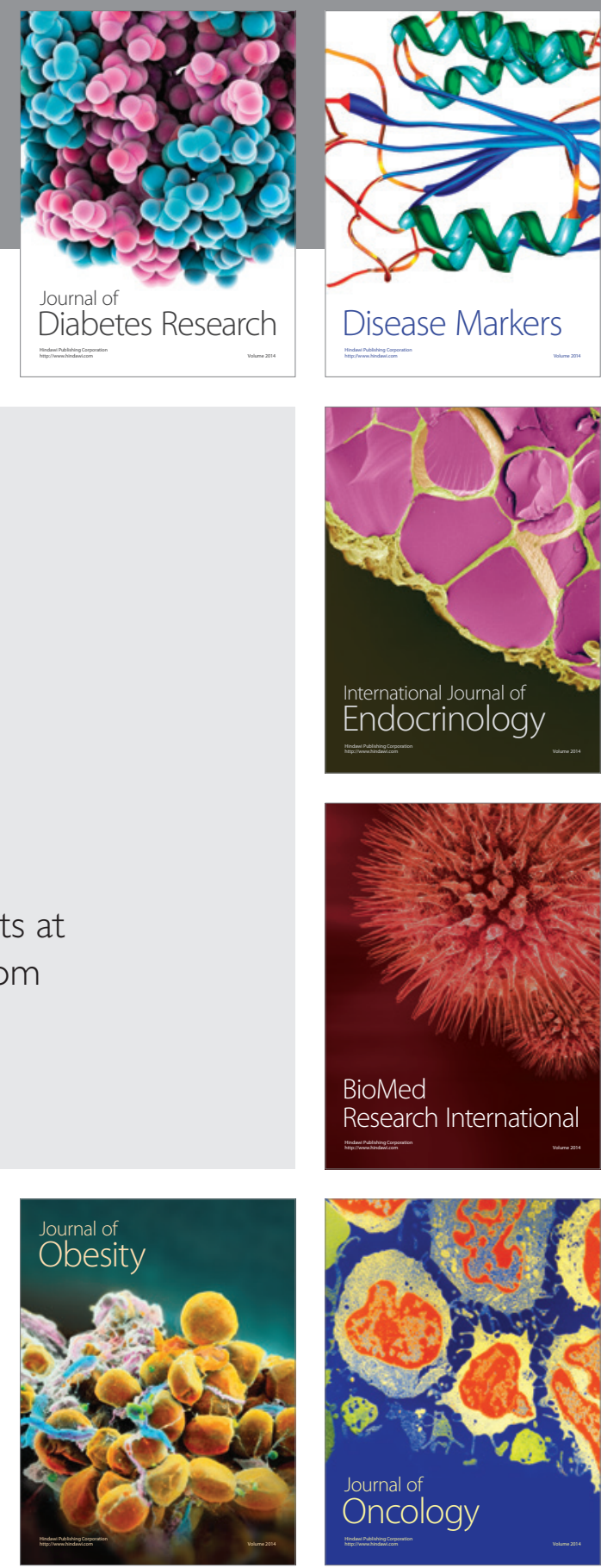

Disease Markers
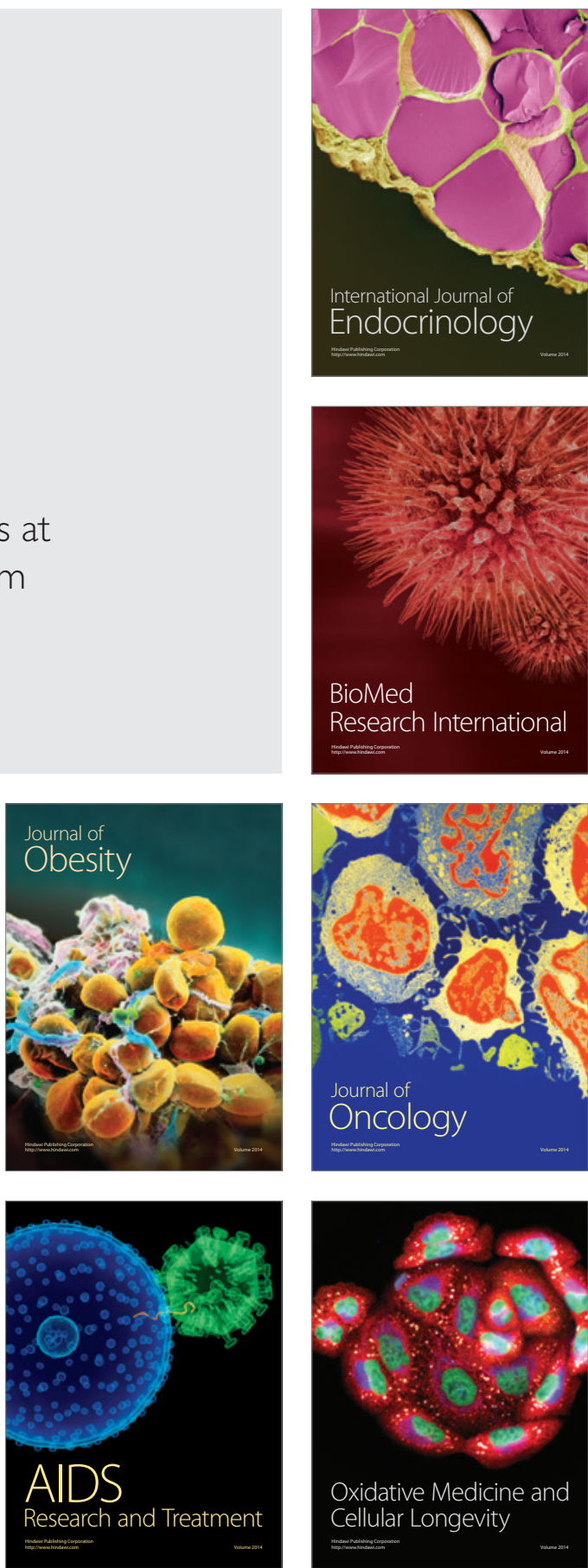